\title{
Role of blister fluid soluble HLA-E In SJS/TEN
}

\author{
Salvador Escamochero ${ }^{1}$, Rosario Cabañas², Ana María Fiandor ${ }^{2}$, Pedro Herranz ${ }^{3}$, Lucia Cachafeiro ${ }^{4}$, Teresa Bellón ${ }^{1 *}$ \\ From 6th Drug Hypersensitivity Meeting (DHM 6) \\ Bern, Switzerland. 9-12 April 2014
}

\section{Background}

Stevens-Johnson syndrome (SJS) and toxic epidermal necrolysis (TEN) are life-threatening hypersensitivity reactions to medications characterized by keratinocyte apoptosis, the formation of subepidermal blisters, and skin detachment. Cytotoxic lymphocytes including CTLs and NK cells seem to be the main effectors of keratinocyte killing. Natural killer cytotoxic activity is regulated through the balance of activating and inhibitory signals delivered by innate receptors, some of which recognize HLA class I antigens. Among them, inhibitory CD94/ NKG2A and activating CD94/NKG2C receptors are specific for the non-classical HLA class Ib molecule HLA-E, and are expressed not only in NK cells but also in subsets of $\mathrm{T}$ lymphocytes. We have previously reported that the activating receptor CD94/NKG2C is overexpressed in lymphocytes from SJS/TEN patients resulting in net activation and lysis of HLA-E+ targets. Moreover, HLA-E was found to be overexpressed in affected skin, and in agreement with previous reports showing soluble HLA-E (sHLA-E) released in response to cell activation, we found sHLA-E in blister fluids from SJS/TEN patients.

\section{Objective}

To explore the impact of sHLA-E in the functional capacities of cytotoxic lymphocytes.

\section{Methods}

Conditioned media enriched in SHLA-E or sHLA-B27 (used as a negative control) were prepared and assayed in $51 \mathrm{Cr}$ release assays using purified CD94/NKG2A+ or CD94/NKG2C+ primary human NK cells as effector cells. Production of IFN- was also investigated. Western blot was performed to study the phosphorylation status of the signal transducing molecule DAP12.

${ }^{1}$ Hospital La Paz Health Research Institute- IdiPAZ, Research Unit, Spain Full list of author information is available at the end of the article

\section{Results}

The cytotoxic activity and the production of IFN- by NKG2C+ NK cells were significantly increased in the presence of sHLA-E. Moreover, increased phosphorylation of DAP12 was detected. In addition, blister fluids from SJS/ TEN patients, were also able to specifically increase the cytotoxic activity of NKG2C+ NK cells, and this effect was reverted in the presence of blocking antibodies against HLA-E.

\section{Conclusion}

sHLA-E acts as an agonist of the activating receptor CD94/NKG2C. The results suggest that sHLA-E molecules in blister fluids may contribute to the massive killing of keratinocytes in SJS/TEN patients by enhancing the activity of NKG2C+ cytotoxic lymphocytes.

\section{Authors' details}

${ }^{1}$ Hospital La Paz Health Research Institute- IdiPAZ, Research Unit, Spain. ${ }^{2}$ Hospital La Paz-IdiPAZ, Allergy, Spain. ${ }^{3}$ Hospital La Paz-IdiPAZ, Dermatology, Spain. ${ }^{4}$ Hospital La Paz-IdiPAZ, Burn Unit, Spain.

Published: 18 July 2014

doi:10.1186/2045-7022-4-S3-P48

Cite this article as: Escamochero et al:: Role of blister fluid soluble HLA-E In SJS/TEN. Clinical and Translational Allergy 2014 4(Suppl 3):P48.

Submit your next manuscript to BioMed Central and take full advantage of:

- Convenient online submission

- Thorough peer review

- No space constraints or color figure charges

- Immediate publication on acceptance

- Inclusion in PubMed, CAS, Scopus and Google Scholar

- Research which is freely available for redistribution 